\title{
Medical Pluralism, Equity and Holism
}

\author{
Florica Marian ${ }^{\mathrm{a}}$ Harald Walach ${ }^{\mathrm{b}}$ \\ a Institute for Complementary Medicine KIKOM, University of Bern, Switzerland \\ bUniversity of Northampton, School of Social Sciences \& Samueli Institute for Information Biology, Northampton, UK
}

Medical pluralism, equity and holism: these are research issues and perspectives arising in the Swiss Programme for the Evaluation of Complementary Medicine (PEK). This evaluation was commissioned by the Swiss Government in order to provide scientific data on 5 complementary therapies (anthroposophic medicine, homeopathy, neural therapy, phytotherapy and traditional Chinese medicine). The aim of PEK was to inform a policy decision about whether or not these disciplines, if provided by physicians in primary care, should be covered by basic health insurance. As PEK assessed a model of primary care which integrated conventional and complementary medicine - by comparing it with conventional primary care - I will also use the denomination 'integrative medicine'. PEK was carried out from 1998 to 2005. In that time, the government as well as the responsible authorities changed and decided against the definitive inclusion of the CAM methods in compulsory health coverage in June 2005. This was a political decision not supported by PEK data, and associated with a lack of fairness at several levels (e.g. exercise of political influence on the research process; the decision-making process itself). As equity and fairness are often neglected issues in the research literature on complementary and alternative medicine (CAM), they are investigated in two articles presented here. Holism, however, is very often mentioned and addressed in CAM research. The PEK data confirm the importance of holism as a core dimension for both physicians and patients. Moreover, they allow to include the aspect of physician satisfaction into a four-dimension model which comprises wholeness of patient, wholeness of physician, integration of therapeutic approaches and a relational dimension.

The thematic focus of this supplement is influenced by my own experience as a researcher participating in the PEK observational studies conducted in Swiss primary care and especially in the study on physicians' philosophy of care. Moreover, the daily confrontation with political and academic pressure and misuse of power motivated me to explore equity issues in more detail. My background in medical and cultural anthropology may also have contributed to a reflection on equity which takes into account both the role of the participant and the role of the observer. As a consequence, three methodological approaches are combined in the articles of this supplement: (1) an empirical approach, (2) a normative approach (a form of ethical enquiry and reflection on what should be or what a fair process would look like, and (3) a theoretical approach (discussing concepts of equity and holism). Such an interdisciplinary approach to both methodology and con- cerned fields, i.e. ethics, political science, primary care and complementary medicine, shows many valuable ways for CAM research. Without questioning the importance of clinical studies and the adaption of biomedical research methods to CAM, this supplement shows the need for new ways in CAM research and for a transfer of knowledge from other fields. One of the lessons to be learnt from PEK is the paradox, that the question about effectiveness of complementary medicine cannot simply be answered through more and more studies on effectiveness! Equally important is a reflection about the reasons, why it is so difficult for CAM research to be acknowledged (as a research field and regarding its results). PEK allows an analysis of equity issues interrelated within an equity circle. This is not only relevant for Switzerland. Anthropological, policy and practice dimensions of equity are identified and linked to different concepts of equity and conceptual frameworks: medical pluralism, cultural imperialism, accountability of reasonableness, distributive justice.

The issues addressed in this supplement are closely connected to two of the four principles of biomedical ethics, i.e. beneficence, non-maleficence, respect for autonomy and justice. So I hope to contribute to acknowledging that respect for autonomy (as closely related to the recognition of medical pluralism), fairness and justice are important issues in research and debate on CAM. Moreover, I hope to show that the dialogue with other fields and disciplines may contribute to sustain the demands for more transparency, democracy and justice in the context of research and health policy.

Florica Marian Bern

Having been on the review board of PEK and having had firsthand experience of the political processes, the chuzpe and the agenda behind the curtains that led to the decision to stop PEK and to decide against the gist of the data, I welcome this issue which brings together highly pertinent and timely reflections. If we do not start to reflect upon the processes governing research, the agenda behind the driving forces, and the motivations of the main actors, we will never understand outcomes, decisions and science as such. Here, an important starting point is being made. I recommend it warmly to everyone.

Harald Walach Northampton

\begin{tabular}{ll}
\hline KARGER & @ 2007 S. Karger GmbH, Freiburg \\
Fax +49 7614520714 & Accessible online at: \\
$\begin{array}{l}\text { E-mail Information@Karger.de } \\
\text { www.karger.com }\end{array}$ & www.karger.com/fok
\end{tabular}

Dr. rer. med. Florica Marian, lic. phil. Kollegiale Instanz für Komplementärmedizin KIKOM

Universität Bern, Inselspital Imhoof Pavillon

CH-3010 Bern, Switzerland

Tel. +41 31 6328606, Fax 6324262

E-mail florence.marian@kikom.unibe.ch 